\title{
Tumor Necrosis Factor Assay
}

National Cancer Institute

\section{Source}

National Cancer Institute. Tumor Necrosis Factor Assay. NCI Thesaurus. Code C17635.

An immunoassay to detect Tumor Necrosis Factor (TNF), which is a potent lymphoid factor, and exerts cytotoxic effects on a wide range of tumor cells and other target cells. Utilizes monoclonal antibody to TNF immobilized on microtitre plate. 